\section{Escolha coletiva, governança e direitos de propriedade: \\ uma análise econômica dos commons}

\section{Palauras-chave \\ direitos de propriedade, commons, governança, \\ bem-estar social.}

Classificação JEL D71, D23, K11.

\section{Key words \\ property rights, commons, governance, social welfare.}

JEL Classification $D 71, D 23$, K11.

\section{Resumo}

No âmbito de uma abordagem ligada ao "Velho Institucionalismo", e utilizando as ferramentas analíticas construídas por Williamson e Ostrom, este trabalho propóe-se analisar as implicaçóes econômicas ligadas ao desenvolvimento dos diferentes sistemas de propriedade coletiva e dos bens comuns. Em uma primeira parte, mostrarei como a literatura concebe o problema dos commons e dos anticommons. Em uma segunda parte, após certas consideraçóes metodológicas, especificarei os diferentes elementos que permitem construir uma função de bem-estar coletiva. Na parte final, definirei o conceito de viabilidade de determinada modalidade de governança e mostrarei por que, a partir do momento em que os custos de transaçáo são positivos, as modalidades de negociação privada náo constituem, sistematicamente, o mecanismo mais eficiente, em termos de bem-estar social.
Alain Herscovici Professor do Programa de Pós-Graduaçáo em Economia (PPGEco/UFES) e Pesquisador do CNPq.

\section{Abstract}

From an approach related to the "Old Institutionalism," and to the analytical tools built by Williamson and Ostrom, this paper aims to analyze the economic implications of the development of different systems of collective Property Rights and of Commons. In a first part, I will show how the economic literature conceives the problem of commons and anticommons. In a second part, after some methodological considerations, I will specify the different elements necessary to built a function of collective welfare. At the end, I will define the concept of viability of a particular mode of governance and I will show why, when the transaction costs are positive, the governance based on private negotiation is not systematically the most efficient mechanism, in terms of social welfare. 


\section{1_Introdução}

A Ciência Econômica continua sendo lúgubre (dismal), como escrevia David Ricardo? A ler a literatura que trata das escolhas coletivas e dos sistemas de Direitos de Propriedade Intelectual (DPI), poderíamos responder afirmativamente a essa pergunta. Tragédia dos commons versus tragédia dos anticommons? Quais são as formas de organização social da produção, do consumo e da propriedade viáveis durante determinado período histórico? O que é trágico para certos economistas pode se tornar uma fonte de felicidade, ou seja, de bem-estar social, para outros.

Este trabalho se situa na linha da economia institucional, mais especificamente dos trabalhos pioneiros realizados por Williamson (2000, 2002) Ostrom (2000) e Ostrom e Hess (2007). O primeiro autor ressalta a especificidade dos ativos e o fato de os contratos serem, por natureza, incompletos; o segundo estuda mais especificamente as diferentes modalidades de produção e de apropriação social diretamente ligada a formas coletivas de propriedade. Neste sentido, este trabalho pretende fornecer elementos para propor uma alternativa em relação às análises oriundas dos escritos de Coase, e que preconizam modalidades de negociaçáo privada.

As análises esenvolvidas neste artigo se aplicam plenamente a diferentes ativida- des sociais: meio ambiente, informação, conhecimento e cultura, produção científica e tecnológica, estruturas cooperativas ou solidárias ligadas à gestão coletiva da terra ou aos diferentes sistemas de microcréditos, entre outros. Não obstante, a economia digital ligada às redes eletrônicas e à internet representa, por excelência, um setor no qual este tipo de estudo se aplica: a natureza de bem público dos serviços produzidos e distribuídos, as novas formas de direitos de propriedade diante da impossibilidade de implementar um sistema de DP privado eficiente e o desenvolvimento das diferentes comunidades on-line são elementos que ressaltam a importância dos componentes comuns, inclusive no âmbito de uma lógica privada, e que tornam necessária a análise econômica dessas modalidades de governança.

A problemática desenvolvida neste trabalho é dupla: consiste em identificar as diferentes variáveis que determinam uma função de bem-estar social, no que diz respeito a determinada coletividade; define igualmente a viabilidade de determinada modalidade de governança, a partir do grau de compatibilidade entre o sistema de Direitos de Propriedade e a natureza econômica dos bens e dos serviços.

Em uma primeira parte, mostrarei como a literatura concebe o problema dos commons e dos anticommons e por que is- 
so é diretamente aplicável à economia digital. Em uma segunda parte, após certas considerações metodológicas, especificarei os diferentes elementos que permitem construir uma função de bem-estar coletiva. Na parte final, definirei o conceito de viabilidade de determinada modalidade de governança e mostrarei como, a partir do momento em que os Custos de Transação (CTs) são positivos, os conceitos definidos neste trabalho permitem escolher uma modalidade de governança específica.

\section{2_Tragédia dos commons, tragédia dos anticommons e DPI: uma primeira abordagem}

\section{1_Comuns versus anticomuns?}

Quando se trata de um bem comum, em determinada coletividade (componentes ecológicos, recursos naturais, conhecimento comum, etc.), a apropriaçáo privada de tais bens pode ser prejudicial para a comunidade, isto é, pode se traduzir pelo esgotamento do estoque disponível.

Hardin (1968, p. 1243) explica o fracasso da propriedade comum da terra, na Inglaterra, no século XVIII, pela ausência de um sistema institucional capaz de preservar o estoque desse bem comum. $\mathrm{O}$ exemplo do lago ilustra esse tipo de situa- ção: se tal lago for um bem comum, cada pescador vai maximizar seu ganho, o que não é compatível com a preservação do estoque de peixes. A solução consiste em implementar um princípio de coerção: a propriedade privada do lago cumpre essa função e permite evitar a exaustão do estoque de peixes. Os limites dessa tese são os seguintes:

I_ No caso da apropriação privada dos recursos que provêm do bem comum, existem outros meios para regular o sistema. Nas diferentes coletividades, há convenções e regras que determinam e controlam as diferentes modalidades de apropriação social desses bens. As diversas formas de propriedade coletiva não podem ser assimiladas à ausência de propriedade (Ostrom, 2000, p. 335): elas geram regras e convençóes explícitas e/ou implícitas que os diferentes membros da coletividade têm de seguir, o que permite controlar os comportamentos oportunistas, amenizar as implicaçóes ligadas a tais comportamentos, para um nível de custo de transação compatível com o 
funcionamento do sistema.

Contrariamente à tese de

Hardin, as enclosures se

explicam a partir da atuação dos fazendeiros mais ricos, ou seja, do nâo respeito das regras que regulavam as modalidades de apropriação privada desse bem comum (Cox, 1986, p. 60).

II_É preciso, igualmente, diferenciar as situações em função da natureza econômica do bem comum. Quando os recursos obtidos do bem comum são bens privados e divisíveis, "the benefits consumed by one individual subtract from the benefits available to others" (Ostrom, 2000, p. 337); mas a situação é diferente quando se trata de bens públicos indivisíveis. De fato, $a$ explicação de Hardin só faz sentido no caso de os bens serem privados e totalmente divisiveis. Quando, ao contrário, se trata de bens públicos distribuídos no seio de redes, as externalidades positivas dependem diretamente da quantidade de usuários/ participantes. No caso das redes eletrônicas, as externalidades de demanda expressam essa relação
(Katz; Shapiro, 1985). Podemos observar a existência desse tipo de externalidade na indústria de softwares e nos sistemas de compartilhamento de arquivos digitais (Herscovici, 2007). $\mathrm{Na}$ presença de bens públicos, as modalidades de apropriação privada desses bens provocam falhas de mercado importantes.

Por outro lado, o nível dos custos de transação necessário para controlar e conter os comportamentos oportunistas que se desenvolvem a partir do caráter não rival desses bens é alto demais (Demsetz, 1964, p. 16).

Os anticommons (Heller; Eisenberger, 1998) se caracterizam pelo fato de o conhecimento ser o objeto de DPIs privados múltiplos; neste caso, o jogo do mercado produz externalidades negativas e importantes falhas de mercado. Há aumento dos custos relativos à aquisiçáo dos diferentes processos necessários à implementaçáo de determinada tecnologia, à medida que os utilizadores têm de negociar esses direitos com vários titulares dos direitos 1. Quando houver vários titulares dos DPIs necessários à adoção de determinada inovação tecnológica, o preço será maior que na situação na qual há apenas um titular. $\mathrm{O}$ desenvolvimen-
${ }^{1}$ A esse respeito, ver
igualmente Posner (2005, p. 69). 
2 Trata-se de externalidades de demanda, no sentido definido pelos novoskeynesianos.

${ }^{3}$ Isso corresponde ao funcionamento das redes de compartilhamento de arquivos, às modalidades de produção e de distribuição dos programas livres e aos scientific commons. to dos comportamentos oportunistas faz com que apareçam externalidades de demanda ${ }^{2}$ : essas externalidades produzem falhas de mercado e se traduzem por uma diminuição do bem-estar.

A privatização das modalidades de apropriação da produção científica e tecnológica se traduz pelo desenvolvimento dos comportamentos predadores e pela queda da taxa de crescimento da produção, em função do caráter cumulativo desse tipo de atividade. Na perspectiva desenvolvida neste trabalho, essas falhas de mercado se explicam pela incompatibilidade entre modalidades de apropriação privada ligadas a um sistema de DPI privado e a produção de bens públicos não rivais e não exclusivos.

Conforme mostram Alchian e Demsetz (1973, p. 23), a tragédia dos commons se explica pela contradição entre a ausência de propriedade, no que diz respeito ao estoque de bens comuns, e a apropriaçáo privada dos bens; se, por exemplo, o fruto da pesca for dividido igualmente entre os diferentes membros da comunidade, independentemente das contribuiçôes individuais, não haveria comportamentos oportunistas. A apropriação privada de um bem público, ou semipúblico, explica a existência e o desenvolvimento dos comportamentos oportunistas.

Existem duas maneiras de controlar ou de eliminar parcialmente esses com- portamentos oportunistas: ou eliminar os DPs privados, no que concerne ao consumo, ou, ao contrário, privatizar a propriedade do bem comum. O primeiro caso corresponde a formas de economia cooperativa nas quais: (a) a apropriação privada não é determinada com base na contribuição individual de cada agente, mas em função de outros princípios de redistribuição; ${ }^{3}$ (b) a propriedade do bem público é coletiva. No segundo caso, trata-se de privatizar o estoque de bem comum; a preservação desse estoque será assegurada a partir do comportamento "racional" do proprietário privado: a exclusão pelos preços permite eliminar os comportamentos oportunistas.

A escolha de uma modalidade de governança será feita, em relação a um mesmo nivel de produção, em função do nivel dos custos de transação relativo a cada uma dessas modalidades; por outro lado, esse nivel dos custos de transação depende diretamente da natureza econômica dos bens e do sistema de DP vigente.

A esse respeito, Barzel (1997, p. 4-5) define os custos de transaçáo como "[...] the costs associated with the transfer, capture and protection of rights". O sistema de DP deve ser compatível com um nível de custos de transação que permita implementar a produção e a distribuição dos bens e dos serviços considera- 
dos. Tal definição é semelhante àquela de Williamson:

"Os custos de transação são constituidos pelas cláusulas de segurança, as penalidades, as assimetrias da informação, os dispositivos de verificação e a resolução dos conflitos por uma instância externa e, obviamente, pelos custos relativos aos contratos" (Williamson, 2002, p. 183).

\subsection{DPI e novas formas de propriedade intelectual}

É na economia digital que as diferentes formas de economia solidárias apresentam a maior eficiência social. Os sistemas dos comuns baseados sobre o compartilhamento de informaçōes e de bens culturais são social e economicamente mais eficientes que os sistemas baseados sobre a propriedade privada e sobre a distribuição a partir de suportes materiais individualizados. Essa eficiência pode ser avaliada em relação à diversidade dos títulos disponibilizados e à ampliação social das modalidades de acesso (Herscovici, 2007).

No que diz respeito à indústria da música, por exemplo, os mecanismos de criaçáo e de apropriaçáo do valor são baseados sobre um sistema de DPI privado, diretamente ligado com modalidades privadas de apropriação, com base em suportes materiais individualizados (livros,
CDs, etc.), e com pagamentos individualizados por parte dos consumidores. Essas modalidades de regulação de mercado correspondem ao modelo analógico que caracterizava as indústrias culturais até a era digital. $\mathrm{O}$ desenvolvimento das redes eletrônicas corresponde a modificaçooes radicais, no que diz respeito às modalidades de produção, de financiamento e de apropriação desses bens: à medida que o modo de apropriação se modificou, o sistema de DPI e de financiamento tem que acompanhar essas evoluçóes (Romer, 2002). De um ponto de vista geral, o desenvolvimento da economia digital se traduz por um duplo movimento: a transformação da natureza econômica dos bens e dos serviços, e dos sistemas de DPI correspondentes.

Por um lado, a maior parte dos bens pode ser assemelhada a bens públicos, cujas principais características são a não exclusão e a não rivalidade. Essa transformação se explica com base na tecnologia, ou seja, na digitalização desses conteúdos; neste caso, a tecnologia (o que Ostrom e Hess (2007, p. 10) chamam de "physical characteristics of the ressource") determina essa natureza econômica. A concorrência consiste em internalizar as externalidades de redes presentes nesses mercados; não se trata de vender bens privados, mas de negociar o acesso às diferentes redes assim constituídas, de "capturar" parte dos consumido- 
res/usuários, e de praticar uma discriminação pelos preços, em função da propensão a pagar dos diferentes grupos. Por outro lado, esses bens são bens de experiência (experience goods) (Varian, 2003): o sistema de preços não divulga para o consumidor as informaçóes relativas à sua qualidade. Outros mecanismos sociais compensam as falhas do sistema de preços: instituiçóes e comunidades on-line, no caso da internet.

As estratégias desenvolvidas consistem, num primeiro tempo, em desenvolver serviços gratuitos, ou semigratuitos, para os diferentes consumidores. Esses mecanismos permitem criar as redes e as externalidades que lhes correspondem, assim como divulgar as informaçóes que o sistema de preços não tem condiçóes de divulgar: vários produtores de softwares disponibilizam gratuitamente seus programas, durante um período limitado. Por outro lado, tendo em vista a ausência de suporte material no que concerne à distribuição (o caso das redes peer to peer ou das diferentes formas de streaming), não é possível controlar nem limitar a pirataria privada: os custos que permitiriam implementar esses processos de controle são proibitivos (Herscovici, 2007).

Em função dessas evoluçóes, novas formas de propriedade coletivas aparecem, isto é, os creative commons e as diferentes formas de copy left. No que diz respeito aos programas livres, a licença GPL ( $G e$ neral Public License) pode ser qualificada de extensiva: se um componente protegido por tal licença for incorporado em outro programa, este outro programa tem de ser regido pelo mesmo tipo de licença. De um ponto de vista mais geral, nessas novas formas de propriedade coletivas, os autores cedem parte de seus direitos privados para criar um bem público (Ostrom; Hess, 2007, p. 17).

\section{3_Uma tipologia dos diferentes tipos de direitos}

A tipologia estabelecida por Ostrom e Hess (2007) ressalta o fato de que existem vários tipos de direito de propriedade (o conceito de feixe de direitos), e que esses direitos se aplicam a diferentes níveis. Utilizarei esta tipologia para distinguir os seguintes direitos:

I_Acesso: o direito de ter acesso a um estoque de bens ou de serviços e de poder utilizá-los. Em função da natureza divisível ou indivisível do bem, as implicaçôes econômicas são diferentes.

II_Contribuição: o direito de contribuir com a preservação/ ampliação do estoque comum, no caso dos scientific commons ou dos programas livres, por exemplo. 
III_Extração: o direito de obter unidades ou produtos do estoque existente. Aqui, também, as implicações, no que diz respeito ao nível do estoque comum, são diferentes em função da natureza divisível ou indivisível dos bens que compóem esse estoque.

IV_ Management/participação: o direito de modificar as regras vigentes no seio do "clube", o que implica modificar a natureza da governança.

V_ Exclusão: o direito de determinar quem pode utilizar os direitos anteriormente definidos. $\mathrm{O}$ sistema de preços constitui uma dessas modalidades.

VI_Alienação: o direito de vender ou de "alugar" os direitos anteriormente definidos. A privatização se traduz pela venda da totalidade desses direitos, como o caso dos direitos de poluição. Por outro lado, o fato de modificar alguns desses direitos implica modificar a natureza econômica dos bens e dos serviços; por exemplo, as modalidades de acesso ao estoque e de extração determinam o caráter público ou privado dos bens.
A passagem de um sistema de DP privado para um sistema comum consiste em ceder alguns desses direitos privados para criar um capital social (Ostrom; Hess, 2007). No caso dos programas livres, a construção desses commons se implementa com base na cessão dos componentes ligados ao acesso e à alienação e no desenvolvimento das atividades ligadas à contribuição dos diferentes participantes.

A natureza econômica dos bens e dos serviços depende de duas variáveis: a evoluçáo tecnológica e o sistema de DP adotado. Um bem em si não é público ou privado; é o sistema de DP, em função da evolução tecnológica, que lhe confere sua natureza econômica. Neste sentido, o sistema de DP tem de ser concebido como uma instituição. Há determinação recíproca entre a natureza econômica dos bens e o sistema de DP: à medida que esses dois componentes não são compatíveis, existem duas soluçôes: (a) adaptar a natureza dos bens ao sistema de DP vigente. Isso pode se traduzir por uma privatização ou uma "publicização" do bem; ou (b) mudar o sistema de DP para que ele seja compatível com a natureza econômica dos bens. A dinâmica da evoluçáo institucional pode ser explicada com base nesse mecanismo; as escolhas dependem dos CTs associadas a cada uma dessas dinâmicas, ou seja, de sua viabilidade. 


\section{3_A construção da função de bem-estar social}

\section{1_Governança, regulação e ótimo social: algumas considerações metodológicas}

Williamson adota a hipótese de racionalidade limitada; neste sentido, a incerteza se justifica a partir da capacidade limitada dos agentes para organizar e obter as informaçôes pertinentes. Qual é a natureza dessa incerteza? São duas as respostas possíveis:

I_ Primeiramente, a incerteza é inteiramente definida pelos limites cognitivos dos agentes, e o universo é ergódico (Slater; Spencer, 2000). Neste sentido, não há incerteza forte, no sentido pós-keynesiano.

II_O segundo tipo de resposta ressalta o fato que há uma relação estreita entre esses dois tipos de incerteza: na presença de comportamentos oportunistas, não é possível prever todos os estados do mundo possíveis. A incerteza comportamental se traduz por incerteza forte, e a especificidade dos ativos é uma variável endógena (Saussier;

${ }^{4}$ A esse respeito, ver Arrow (1974, p. 8).
Yvrande-Billon, 2007, p. 75). Isso explica a existência de estratégias que visam a auferir as rendas de monopólio com base no sistema de DPI vigente.

Aqui, a interpretação de Williamson se relaciona diretamente com o segundo tipo de resposta: a existência de uma incerteza forte ressalta as diferenças entre Coase e Williamson e permite justificar as hipóteses feitas por esses dois autores em relação à natureza dos contratos. Coase adota a hipótese de racionalidade substantiva e de não especificidade dos ativos. Apesar de sua ruptura aparente com a análise neoclássica, Coase mantém relação ontológica com o modelo walrasiano e adota as mesmas hipóteses: racionalidade substantiva e ergodicidade.

Para outros economistas institucionalistas, os contratos são incompletos, e o sistema de DP, "imperfeito", por natureza. A esse respeito, Barzel (1997, p. 4) afirma que custos de transação positivos correspondem ao fato de os agentes não possuírem uma informação perfeita (full knowledge) a respeito do ativo e dos retornos esperados. Essas imperfeiçóes se explicam, simultaneamente, pelas diferentes assimetrias da informação e pelo caráter não ergódigo do universo. ${ }^{4}$

Uma vez admitida a hipótese de incerteza forte, surge a seguinte contradição: a problemática construída por Williamson consiste em escolher a modalidade de go- 
vernança que economiza os custos de transação, para determinado nível de especificidade dos ativos (2002, p. 180). Se os agentes econômicos minimizam os custos de transação, isso implica que eles atuam valendo-se de uma racionalidade substantiva, em um universo ergódico. Não obstante, é impossivel conciliar racionalidade limitada e náo ergodicidade com escolhas que minimizam os custos de transação. Em última instância, se consideramos que o universo é ergódico, os custos de transaçâo são negligenciáveis no longo prazo, e o mercado representa a instância de regulação mais eficiente (Slater; Spencer, 2000, p. 79; Langlois; Robertson, 1995).

No âmbito de uma perspectiva ligada ao "Velho Institucionalismo", escolho a tese da incerteza forte: tal escolha não permite minimizar os custos de transação, mas chegar a uma situação intermediária entre o nível mais alto e o mais baixo, isto é, nível julgado satisfatório (satisfacing approach, Williamson, 2002, p. 174). É possivel estabelecer um paralelo entre essa concepção da governança e o conceito de modo de regulação, no sentido definido pela Escola Francesa da Regulação. Esses dois conceitos são concebidos independentemente de qualquer processo de maximização micro ou macroeconômica; tal interpretação ressalta, ao contrário, a historicidade e o papel das instituiçóes no processo de regulação.
O sistema de DPI não é concebido como um instrumento que permite minimizar os custos de transação, mas como uma instituição, na qual variáveis econômicas e sociais são incorporadas. Nesta abordagem, obviamente, o mercado não é uma instância autônoma e autorreguladora; o preço não é determinado a partir do jogo da oferta e da demanda, mas ele é, essencialmente, uma convenção social (Hodgson, 1998, p. 175) ou o produto das crenças coletivas (Orléan, 2006, p. 3).

\section{2_Os determinantes da função de bem-estar social}

A formalização simples que vou apresentar agora tem por principal objetivo construir uma função de bem-estar social, identificar as principais variáveis determinantes e, por fim, mostrar em que medida o tipo de governança determina esse bem-estar social.

Em função das escolhas epistemológicas e metodológicas feitas aqui, estudarei os diferentes mecanismos de regulação dos diferentes sistemas sociais em função do jogo das compatibilidades/incompatibilidades entre variáveis institucionais e variáveis econômicas, independentemente de qualquer mecanismo de maximização micro, meso ou macroeconômico.

A função de bem-estar social, aplicável ao nível das diferentes coletividades, 
depende das seguintes variáveis: a quantidade consumida individualmente $q i$, o nível inicial do estoque disponível para a coletividade, $N$, o nível dos custos de transaçáo que corresponde àquela modalidade de governança, $C T$, e os mecanismos de exclusão, Ex. Esses são determinados a partir do sistema de DP vigente; no caso de um sistema de DP privado, a exclusão se concretiza pelos preços que condicionam o consumo individual, ou seja, o acesso ao estoque disponível.

A função de bem-estar social é a seguinte:

$$
\mathrm{Uw}=\mathrm{f} 1(\mathrm{qi}, \mathrm{Nj}, \mathrm{CT}, \mathrm{Ex})
$$

Temos as seguintes relaçóes:

$\mathrm{dUw} / \mathrm{dqi}>0$

$\mathrm{dUw} / \mathrm{dNj}>0$

Os componentes ligados à produção (à provisão dos bens) são diretamente incorporados nessa função, via funçáo de estoque. As relaçóes (2) e (3) expressam o fato de que o bem-estar social aumenta quando aumenta o nível do estoque e o consumo individual, o que é bastante óbvio.

Os efeitos de uma intensificaçáo dos mecanismos de exclusão são mais complexos, à medida que eles dependem da natureza dos bens que constituem o estoque.
A tragédia dos commons corresponde à seguinte relação:

$\mathrm{dUw} / \mathrm{dEx}>0$,

no caso de um bem privado

A exclusão permite preservar o estoque e assegurar o consumo futuro; trata-se de uma escolha intertemporal de consumo de bens escassos.

No caso de um bem público puro, no sentido definido por Samuelson (1954), os efeitos da exclusão são diferenciados; à medida que o consumo não gerou congestionamento, temos:

$\mathrm{dUw} / \mathrm{dEx}<0$

A exclusão diminui o bem-estar social, à medida que o caráter indivisível do bem público permite aumentar o consumo individual sem diminuir o estoque disponível.

Esse efeito é ampliado quando há externalidades de redes (Katz; Shapiro, 1985): independentemente de qualquer nível de consumo, a exclusão diminui a qualidade indivisível do serviço. $\mathrm{O}$ mesmo tipo de observação se aplica às atividades que apresentam caráter cumulativo, como a produção científica e tecnológi- 
ca, por exemplo (Nelson, 2003). Esse caso concerne diretamente à tragédia dos anticommons.

Quando os bens são bens de experiência, a relação (4.2) é igualmente verificada: já que o sistema de preços não fornece as informaçóes qualitativas necessárias; é preciso compartilhar a experiência dos diferentes usuários, para poder aumentar a utilidade do consumo. Assim, quanto maior o número de usuários, maior a utilidade de cada usuário. Esse fenômeno caracteriza a economia das redes eletrônicas, tanto o hardware quanto o software, e ressalta o papel econômico das diferentes comunidades on-line.

$\mathrm{dUw} / \mathrm{dEx}>0$

$\mathrm{dUi} / \mathrm{dq}>0$

Quando existem processos cumulativos de aprendizagem, no caso na economia digital, ou quando os bens são altamente diferenciados (o caso dos bens culturais, por exemplo), a utilidade marginal desses bens é crescente.

$\mathrm{dUi} / \mathrm{dp}<0$

Quando o consumo alcançou o valor crítico, aparecem efeitos de congestionamento: a qualidade indivisível diminui para cada um dos participantes. Neste caso, a exclusão, que permite limitar o consumo, pode ser implementada valendo-se de um sistema de preços, ou de outros critérios institucionais, a saber: regras, princípios de coerção, etc.

Uma das limitaçóes das conclusôes de Hardin consiste no fato de que

O nível do estoque de bem comum pode ser representado da seguinte maneira:

$\mathrm{Nj}=\mathrm{f3}$ (qi)

$\mathrm{dNj} / \mathrm{dqi}<0$

É o caso particular analisado por Hardin; essa relação é igualmente ve- 
rificada quando aparecem efeitos de congestionamento.

$$
\mathrm{dNj} / \mathrm{dqi}=0
$$

Quando se trata de um bem público indivisível, sem efeitos de congestionamento e sem externalidades de redes.

$$
\mathrm{dNj} / \mathrm{dqi}>0
$$

Quando há externalidades de redes ou quando os processos de produção são cumulativos.

Finalmente, há uma correlação negativa entre os custos de transação e o bem-estar:

$$
\mathrm{dUw} / \mathrm{dCT}<0
$$

Podemos afirmar, assim, que o bem-estar social depende diretamente da compatibilidade entre a natureza econômica dos bens e o sistema de DP vigente, relativo ao estoque e ao consumo individual; a manutenção ou o crescimento do estoque disponível para a coletividade e o nível dos custos de transação dependem diretamente do grau de compatibilidade entre esses elementos. Por exemplo, a tragédia dos commons se explica a partir da não compatibilidade entre a natureza coletiva do estoque, o consumo privado e o caráter divisível dos bens que constituem esse estoque; a tragédia dos anticommons, pela não adequaçáo entre o caráter indivisível e cumulativo da produção, e o consumo privado. Finalmente, o problema relativo às redes de compartilhamento de arquivos digitais se relaciona com o caráter indivisível do estoque e com umas lógicas de oferta e de consumo ligadas a um sistema de DPI privado e individualizado (Romer, 2002); os custos de transação necessários para controlar os comportamentos "oportunistas" seriam maiores que os ganhos que esse tipo de ação tenta preservar (Herscovici, 2007).

No entanto, é preciso comparar os critérios tradicionalmente utilizados para avaliar o bem-estar social com a função construída aqui:

I_Em termos de justiça redistributiva, o critério de Pareto é relativo, à medida que ele corresponde a um processo de maximização, para uma distribuição de renda determinada exogeneamente.

II_O critério de Kaldor-Hicks, no âmbito de um universo neoclássico, no qual os contratos são completos, e a racionalidade, substantiva, considera unicamente a 
utilidade total ligada à maximização da produção, independentemente de uma ampliação das desigualdades (Herscovici, 2010).

III Finalmente, a função de bemestar, da maneira como ela foi definida aqui, incorpora essas duas dimensóes: a primeira ligada à produção total, em função do nível de estoque, e a segunda, de ordem distributiva, com base nos sistemas de DP que determinam a exclusão ou a inclusão social.

\section{4_Sistema de DP, natureza econômica dos bens e viabilidade do modo de governança}

\section{1_Os diferentes níveis de aplicação dos DPs}

É preciso fazer as seguintes observações: primeiramente, o sistema de DP se relaciona simultaneamente com as modalidades de acesso ao estoque e com as modalidades de consumo. ${ }^{5} \mathrm{O}$ primeiro mecanismo depende diretamente das diferentes lógicas de exclusão: é possível imaginar o livre acesso para os membros de determinada comunidade/coletividade, e a exclusão, por regra, para os agentes que náo pertencem a essas comunidades.

O segundo nível se relaciona diretamente com as modalidades de apropriação individual, ou seja, com o conceito de enforcement utilizado por Alchian e Demsetz (1973, p. 17):

I_ No caso das redes de compartilhamento de arquivos digitais (e-mule, por exemplo), há mecanismos que impóem uma razão entre o download e o upload (Herscovici, 2007); assim, cada usuário tem uma participação mínima na renovação do estoque comum.

II_ No caso dos programas livres, como Linux, parte dos usuários contribui para melhorar o programa, socializando suas próprias contribuiçóes. Os membros da coletividade podem ser usuários, ou seja, apenas utilizar os programas, mas eles podem igualmente contribuir para a complexificação desse programa tendo como base as modificaçóes do código fonte; nesse caso, essas modificaçóes são obrigatoriamente
${ }^{5}$ Ver Heller e Ostrom (2007, p. 10): o ressource system corresponde ao estoque; as resource units, às modalidades de consumo. 
disponibilizadas para o conjunto dos usuários.

Finalmente, valendo-se do conceito de scientific commons, a produção científica (e as aplicaçóes tecnológicas decorrentes) funciona da mesma maneira.

É importante observar que os usuários que acessam a rede criam utilidade social e, consequentemente, valor para os agentes que têm condiçóes de valorizar as modalidades de acesso a essa rede; é a estratégia desenvolvida, com sucesso, por Google, por exemplo. Neste caso, que caracteriza boa parte das atividades desenvolvidas no âmbito da economia digital, a configuração do sistema de DP compativel com a viabilização econômica das atividades de redes deve permitir verificar as seguintes condiçóes: (a) o livre acesso ao estoque de informações disponíveis; (b) o fato de os bens que compóem esse estoque serem indivisíveis; (c) a propriedade privada no que diz respeito às modalidades de acesso à rede, quando essas modalidades geram valor: as empresas que anunciam no Google. Os itens (a) e (b) correspondem à criação da utilidade social necessária à valorização da rede, e (c), a suas condiçôes de valorização, no âmbito de uma lógica privada. Neste caso, é possível falar em propriedade semicomum no que diz respeito ao estoque: há open acess para os consumidores finais, mas acesso pago para as empresas, tendo em vista que o pagamento depende diretamente da utilidade social da rede, ou seja, do open acess por parte dos consumidores finais.

\section{2_A viabilidade da modalidade de governança}

O problema da viabilidade, ou da inviabilidade, surge quando aparecem incompatibilidades entre os diferentes elementos do sistema, e quando a resolução desses antagonismos não pode ser implementada sem custos de transação proibitivos. É possível definir a viabilidade da governança da seguinte maneira: uma governança é viável quando os CTs são compativeis com o nivel da produçáo dos bens e dos serviços, ou seja, quando a implementação da atividade náo se traduz por uma queda do bem-estar. Numa perspectiva intertemporal, é importante observar que a viabilidade se traduz igualmente pela preservação e/ou pela ampliação do estoque disponível.

O conceito de viabilidade definido dessa maneira é alheio a qualquer mecanismo de maximização produzido "naturalmente" por uma hipotética mão invisível. 


\section{Quadro 1_Governança, bem-estar social e viabilidade}

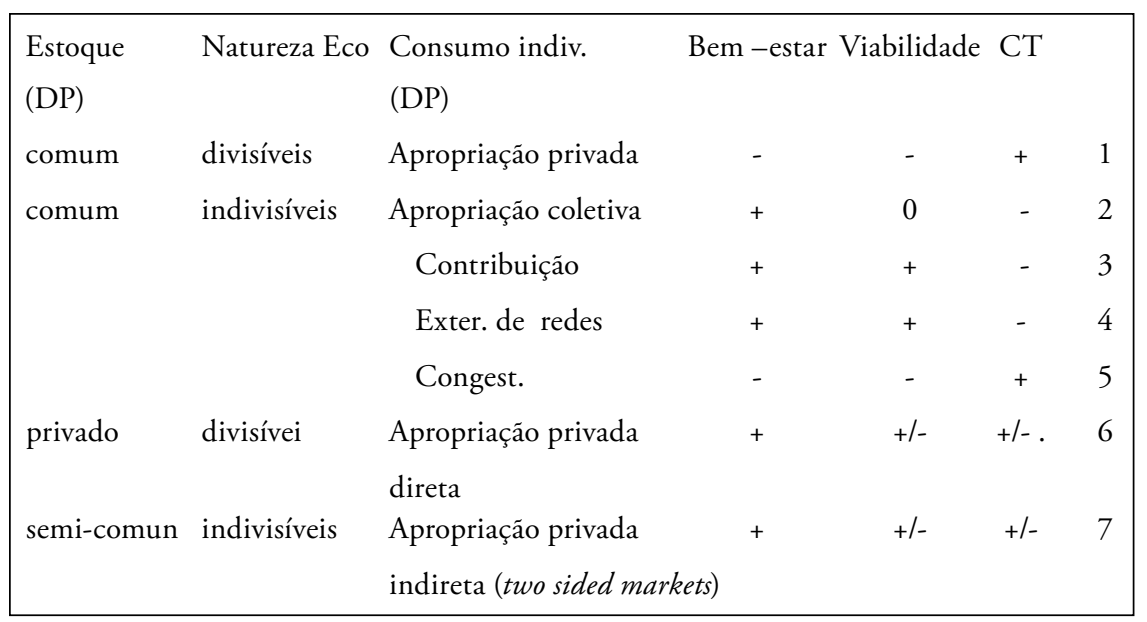

O caso 1 corresponde à análise de Hardin: a inviabilidade se traduz pelo esgotamento do estoque disponível e pelo fato de os CTs serem particularmente altos.

Os casos 2, 3 e 4 correspondem a modalidades de governança/regulação viáveis: as variáveis institucionais permitem manter o nível dos CTs compatível com o bem-estar e não provocam o esgotamento do estoque.

O caso 5 ressalta a necessidade de um controle do consumo social; neste caso, essas atividades de monitoramento se traduzem por aumento dos CTs e, consequentemente, por diminuição do bem-estar. $\mathrm{O}$ problema consiste em determinar se o aumento dos CTs é inferior à perda de bem-estar provocada pelo congestionamento.

A situação 6 corresponde a uma lógica puramente privada, no que diz respeito à produção e ao consumo. $\mathrm{Pa}$ ra a escola neoclássica, essa situação é a mais eficiente: (a) ela maximiza o bem-estar; (b) ela corresponde a CT nulos. Isso só é verificado no caso de um mercado concorrencial, no sentido walrasiano: na ausência de comportamentos oportunistas e quando o sistema de preços fornece gratuitamente a totalidade da informação necessária à realização das trocas. 
Se essas condiçóes não forem verificadas, nada indica que o mercado concorrencial corresponda à governança que tem o menor nível de CT. A análise de Akerlof (1970), a respeito dos carros de segunda mão, chega aos mesmos resultados: o mercado não é eficiente, pelo fato de não representar a solução que, sistematicamente, maximiza o bem-estar.

Finalmente, a situação 7 corresponde aos mecanismos que atuam na economia digital: o estoque é privado, mas os bens são indivisíveis; o consumo é parcialmente gratuito, mas, em função das estratégias dos double sided markets, as modalidades de acesso às redes de usuários representam novas modalidades de apropriação privada da utilidade social assim criada (Bomsel, 2007): os consumidores/ usuários produzem a utilidade social que permite a viabilizaçáo econômica da rede valendo-se da privatização de certas modalidades de acesso a essa rede. Os resultados, em termos de bem-estar e de viabilidade, parecem positivos: a gratuidade, ou semigratuidade, constitui uma melhoria do bem-estar.

Não obstante, a viabilidade desse sistema depende da evolução do sistema de DPI. O sistema atual de direitos autorais é baseado sobre um consumo individual, na base de suportes materiais individualizados (livro, CDs, DVDs, etc.), enquanto a fonte de criação do valor não é mais ligada a esse consumo individual, mas, ao contrário, à criação de utilidade social: Google soube utilizar tal estratégia. Os CTs necessários para controlar as diferentes formas de "pirataria", em relação ao sistema de DPI vigente, são altos e podem inviabilizar a governança privada; é preciso imaginar outras formas de remuneraçáo dos criadores, em sintonia com essas evoluçóes econômicas.

\section{5_A escolha de um modo de governança}

\section{1_0 critério utilizado para avaliar o bem-estar}

Esta análise permite definir precisamente a crítica que Coase (1960) faz a Pigou, quando ele afirma, a respeito das externalidades negativas, que

"Pigou is, of course, quite right to describe such actions as 'uncharged disservices'. But he is wrong when he describes these actions as 'anti-social'” (1960, p. 18).

Assim, segundo Coase, o bem-estar social corresponde à maximização da utilidade coletiva, independentemente de qualquer lógica de redistribuição, ou de um eventual aumento da desigualdade. 
$\mathrm{Na}$ medida em que o critério de $\mathrm{Pa}$ reto incorpora uma dimensão redistributiva, a concepção coasiana não é eficiente. Esta análise torna necessária a construção de outro critério para poder avaliar o bem-estar social: o critério de Kaldor-Hicks. O mecanismo é o seguinte: se A realiza um ganho de $100 \$$, mas produz uma externalidade negativa de $30 \$$ para $\mathrm{B}$, e se $\mathrm{A}$ indeniza $B$ para um valor de $30 \$$, essa situação corresponde a um ótimo de Pareto: nenhum indivíduo prefere outro estado, e o aumento da produçáo total é de $70 \$$. Nesse raciocínio simplificado ao extremo, os custos de transação são nulos.

Mas, quando os custos de transação são positivos, a indenização dos agentes prejudicados não é efetiva nem sistematicamente realizada. Pode-se supor que os custos de transaçáo sejam de $80 \$$, e a externalidade negativa, de $30 \$$. Se a indenização for efetivamente realizada, a utilidade total vai diminuir de $10 \$$; se, ao contrário, a indenização não for realizada, a utilidade total aumenta de $70 \$$. O estado que corresponde a não efetivação da indenização é eficiente em relação ao critério de Kaldor-Hicks, à medida que a produção total aumenta; mas ele não é eficiente em relação ao critério de Pareto. O critério de Kaldor-Hicks corresponde ao aumento da utilidade social, ou seja, a uma alocação eficiente dos direitos, em relação ao aumento da produção; mas ele ignora as implicaçóes em termos de distribuição da renda e de desigualdade. Se a utilidade total aumenta, os desvios entre os poluidores e os poluídos aumentam igualmente.

A aplicabilidade do critério de Kaldor-Hicks depende diretamente das seguintes hipóteses: (a) os direitos dos diferentes agentes são totalmente identificáveis e quantificáveis; (b) esses direitos são transferíveis de um agente para outro; (c) os custos relativos ao controle dos comportamentos oportunistas não são proibitivos. No caso dessas hipóteses serem verificadas, o mercado representa o modo de governança mais eficiente.

\section{2_A problemática coasiana}

Apesar de suas diversas limitaçóes, o teorema de Coase enunciado por Stigler (1966) permite dar uma primeira definição da dicotomia privado/público, no que concerne às modalidades de internalização das diferentes externalidades. Esse teorema pode ser ilustrado pelo seguinte exemplo: ${ }^{6}$ vamos supor que dois agentes econômicos, $\mathrm{X}$ e $\mathrm{Y}$, tenham cada um uma casa, e que $Y$ resolva querer testar sirenas. Essa atividade se traduz por um aumento da utilidade avaliado a 500 para $\mathrm{Y}$, e por uma diminuiçáo da utilidade de 200 para $X$.

\footnotetext{
${ }^{6}$ Este exemplo provém de Pejovich (1995).
} 
Quadro 2_Coase versus Williamson

\begin{tabular}{|c|c|c|c|c|}
\hline \multicolumn{5}{|c|}{ A análise de Coase: a negociação privada } \\
\hline & Utilidade de X & Utilidade de $Y$ & Utilidade total & \\
\hline Sem alarme & 1.200 & 1.000 & 2.200 & 1 \\
\hline Com alarme & 1.000 & 1.500 & 2.500 & 2 \\
\hline Com negociação & 1.200 & 1.300 & 2.500 & 3 \\
\hline Sem negociação & 1.000 & 1.500 & 2.500 & 4 \\
\hline \multicolumn{5}{|c|}{ A alternativa institucional } \\
\hline Regulação pigouviana & 1.200 & 1.000 & 2.200 & 5 \\
\hline Taxa pigouviana & 1.300 & 1.200 & 2.500 & 6 \\
\hline $\begin{array}{l}\text { Regulação } \\
\text { institucional }\end{array}$ & 1.200 & 1.300 & 2.500 & 7 \\
\hline
\end{tabular}

Proposição 1: a utilidade social é maior com a implementação da atividade, conforme ressalta a comparação entre 1 e 2.

Proposição 2: quando os custos de transação são nulos, no âmbito de uma negociação privada, $o$ bem-estar social é independente da alocação inicial dos DPs. As situaçôes 3 e 4 ilustram essa afirmação.

Proposiçâo 3: em termos de bem-estar social, a negociação privada é preferível à regulação estatal, conforme mostra a comparação entre 3 e 4 de um lado, e 5 do outro lado. Neste caso, essa regulação consiste em impedir a implementação da atividade econômica que produz externalidades negativas.

Proposição 4: a comparação entre 3, 4, 6 e 7 mostra claramente que essas situações são equivalentes, do ponto de vista do bem-estar social, quando os custos de transação são iguais a zero.

$S e$, ao contrário, consideramos que cada solução se caracteriza por custos de transação positivos, a eficiência de cada modalidade de governança depende dos niveis de custos de transaçáo respectivos; nada indica que a negociação privada corresponda ao menor nivel de custos de transação (Herscovici, 2012). O caso dos CTs positivos se justifica plenamente: eles representam os custos necessários à implementação e à transferência dos DPs. O fato de considerar CT nulos significa que os DPs são totalmente definidos, que sua implementação se opera "naturalmente" sem custo social, e que os contratos são completos: estamos no caso walrasiano, e não numa perspectiva institucionalista (Barzel, 1997, p. 11).

O bem-estar gerado por cada modo de governança depende dos custos de transação que lhe são associados. Coase, $a$ priori, considera que os custos de transação 
próprios à negociação privada são menores que aqueles que correspondem a uma intervenção pública, isso em função da ineficiência que caracteriza a gestão burocrática. Williamsom (2002), ao contrário, mostra que o mercado, ou seja, a negociação privada, não corresponde, sistematicamente, à solução mais eficiente.

A partir do momento que os CTs são positivos, a escolha da modalidade de governança será efetuada em função: (a) de sua viabilidade; (b) das implicações em termos de manutenção/ampliação do estoque; (c) do bem-estar que lhe corresponde.

\section{6_Conclusão}

Em última instância, esta linha de pesquisa corresponde a uma redefinição do objeto da Ciência Econômica: não se trata mais de estudar como um sistema de preço concorrencial permite alocar recursos escassos, produzir a partir de uma minimização dos custos e alcançar um estado de ótimo social:

I_O sistema de preços fornece um sinal imperfeito no que diz respeito aos componentes qualitativos dos produtos e dos serviços (Grossman; Stiglitz; (1976), e Akerlof (1970) e não permite realizar uma alocação eficiente dos fatores produtivos.
II_Uma série de avanços tecnológicos produziu uma abundância de certos fatores de produção: (a) os aumentos da produtividade do trabalho se traduziram por uma queda do valor dos bens, o que permite falar em abundância relativa; (b) a digitalização da Informação e do Conhecimento, paralelamente com o desenvolvimento das redes eletrônicas, diminui substancialmente a escassez desse tipo de serviço.

Consequentemente, o objeto da Ciência Econômica se modificou. As atividades relativas às modalidades de governança tornaram-se fundamentais, isto é, elas se relacionam diretamente com as modalidades concretas de apropriação social dos bens e dos serviços produzidos, com a perenidade dessa governança, ou seja, com os problemas de coordenação das diferentes atividades e com sua viabilidade social e econômica.

No âmbito de tal perspectiva, o estudo dos custos de transação é fundamental: ele permite escolher determinada modalidade de governança e garantir sua viabilidade. Trata-se de uma análise institucionalista, à medida que o mercado não é concebido como um mecanismo social 
autônomo, socialmente eficiente e desprovido de dimensão histórica. Os componentes institucionais, largo senso, cumprem um papel fundamental: permitem assegurar a regulaçáo do sistema a partir da compatibilidade entre as lógicas de acumulação do capital e as diferentes formas institucionais, coordenar a atuação dos agentes e manter os custos de transação a um nível que seja compatível com o funcionamento do sistema. 


\section{Referências bibliográficas}

AKERLOF, G. The market for "lemons": Qualitative uncertainty and the market mechanism. Quartely Journal of Economics, p. 89, Aug. 1970.

ALCHIAN, Armen A.; DEMSETZ, Harold. The property rights paradigm. The Journal of Economic History, vol. 3, n. 1, p. 16-27, 1973.

ARROW, Kenneth J. Limited knowledge and economic analysis. American Economic Review, March 1974.

BARZEL, Yoram. Economic Analysis of Property Rights. Cambridge University Press, 1997.

BOMSEL, Olivier.

Gratuit! Du déploiement de

l'économie numérique.

Paris: Folio Actuel, 2007.

COASE, R. H. The problem of social cost. Journal of Law and

Economics, 3, 1960.

COX, Susan Jane Buck. No tragedy on the commons, discussion papers. Workshop in Political Theory and Policy Analysis. Indiana University, 1986.

DEMSETZ, Harold. The exchange and enforcement of property rights. Journal of Law and Economics, vol. 7, p. 11-26, 1964.
GROSSMAN, S. J.; STIGLITZ, J. E. Information and competitive price system. American Economic Review, vol. 66, n. 2, May 1976.

HARDIN, Garret. The tragedy of the commons. Science, vol. 162, p. 1243-1248, 1968.

HELLER, M.; EISENBERGER, R.

Can patent deter innovation?

The anticommons tragedy in biomedical research. Science, vol. 29, p. 698-701, 1998.

\section{HERSCOVICI, Alain.}

Information, qualité et prix:

Une analyse économique

de l'internet et des réseaux

d'échange d'archives. Congrès

International Online services ADIS/

Université de Paris Sud. Paris,

Décembre 2007.

HERSCOVICI, Alain. Intellectual property rights, assets specificity and strong uncertainty:

An approach in terms

of "institutional form". 12th

Conference of the Association for

Heterodox Economics, Université de Bordeaux, juil. 2010.
HERSCOVICI, Alain. Informação, Conhecimento e Direitos de Propriedade Intelectual: os limites dos mecanismos de mercado e das modalidades de negociação privada.* A contribuição de Williamson à análise dos Direitos de Propriedade Intelectual. Economia e Sociedade (UNICAMP. Impresso), v. 21, p. 54-72, 2012.

HODGSON, Geoffrey M. The approach of institutional economics. Journal of Economic Literature, vol. 36, issue 1, p.166192, March 1998.

KATZ, M. L.; SHAPIRO,

C. Network externalities, competition and compatibility. American Economic Review, vol. 75, n. 3, 1985.

LANGLOIS, R. N.; ROBERTSON, P. L. Firms, markets and economic changes. London, Routledge, 1995.

NELSON, R. Markets and the scientific commons. WP, Columbia University, 2003.

ORLÉAN, André. Connaissance et finances: De l'hypothèse du futur à l'hypothèse conventionnelle, manuscript, 11 juin 2006.
OSTROM, Elinor. Private and common property rights, workshop. Political Theory and Policy Analysis, Population and Environmental Change. Indiana University, 2000.

OSTROM, Elinor; HESS,

Charlotte. A framework for analyzing the knowledge commons. Understanding Knowledge as a Commons. Edited by Charlotte Hess and Elinor Ostrom, The Mit Press, Cambridge, Massachusetts, London, England, 2007.

PEJOVICH, S. Economic analysis of institutions and systems. Kluwer Academic Publishers. International Studies in Economics and Econometrics, vol. 33,

Dordrecht-Boston, Londres, 1995.

POSNER, Richard A.

Intellectual property: The law and economics approach. Journal of Economic Perspectives, vol. 19, n. 2, p. 57-73, Spring 2005.

SLATER, Gary; SPENCER, David. The Uncertain Foundations of Transaction Costs. Journal of Economic Issues, vol. XXXIV, n. 1, March 2000.

ROMER, Paul. When should we use intellectual property rights. American Economic Review, vol. 92, n. 2, May, 2002. 
SAUSSIER, Stéphane; YVRANDEBILLON, Anne. Économie des Coûts de Transaction. Paris: La Découverte, 2007.

SAMUELSON, Paul A. The pure Theory of Public Expenditure. The Review of Economics and Satisitics, vol. 36, issue 4, p. 387389, 1954.

STIGLER, George J. The Theory of Price. $3^{\text {e }}$. ed.. New York, Macmillan \& CO, 1966.

GROSSMAN S. J.; STIGLITZ, J.

E. Information and Competitive

Price system. The American

Economic Review, vol,66, n. 2, 1976.

VARIAN, H. R. Economics of Information Technology, 2003.

WILLIAMSON, Oliver E. The new institutional economics: Taking stock, looking ahead. Journal of Economic Literature, vol. XXXVIII, Sept. 2000.

WILLIAMSON, Oliver E.

The Theory of the Firm as

Governance Structure: From

choice to contract. Journal of

Economic Prospective, vol. 16, n. 3, Summer 2002.

E-mail de contato do autor:

alhersco.vix@terra.com.br

Artigo recebido em outubro de 2010 aprovado em novembro de 2011 
